\title{
Sensory perception of Brazilian petit suisse cheese by a consumer panel using three-way internal and external preference maps
}

\begin{abstract}
This paper aims to study the sensory perception of Brazilian petit suisse cheese. Physicohemical (total sugar, total acidity, moisture, $\mathrm{L}^{*}, \mathrm{a}^{*}, \mathrm{~b}^{*}$ and soluble solids) physical (texture profile analysis- hardness, cohesiveness and gumminess) and sensory (color, appearance, taste, consistency and overall liking) analyses were performed. Three-way internal and external preference maps were used to evaluate the sensory profile of five different brands of strawberry flavor petit suisse (the only differences between them were the hydrocolloid bulking agents added) correlating with physical and physicochemical parameters. For this, the sisvar and sensoMaker software were used. According to the results, there is variation in the formulations of the petit suisse cheeses that are currently marketed in Brazil, with the exception of total acidity, moisture, and luminosity. Furtherore, Brazilian consumers prefer petit suisse cheese that has intermediate sweetness $\left(7.67^{\circ} \mathrm{Bx}\right.$ to $11.67^{\circ} \mathrm{Bx}$ ) and reject those that are very sweet. In addition, products made with gelatin, pectin and locust bean and guar gums are more accepted.
\end{abstract}

Keywords: petit suisse cheese, sensory analysis, multivariate analysis, consumer profile, gums
Volume 8 Issue 3 - 2020

\author{
Patrícia Aparecida Pimenta Pereira,' Vanessa \\ Rios de Souza, ${ }^{2}$ João de Deus Souza \\ Carneiro ${ }^{2}$ \\ 'Department of Food, Federal University of Ouro Preto, Brazil \\ ${ }^{2}$ Department of Food Science, Federal University of Lavras, \\ Brazil
}

Correspondence: Patrícia Aparecida Pimenta Pereira, Department of Food, Federal University of Ouro Preto, 35400000 , Ouro Preto, Brazil,Tel: +5535984356446. Email patricia.pereira@ufop.edu.br

Received: July II, 2020 | Published: September 09, 2020

\section{Introduction}

Petit-suisse cheese, which was developed by Charles Chervais in 1850 , is made with skim milk and added cream. The cheese is characterized by being a fresh and smooth cheese. In most cases, its texture resembles a thick yogurt. Usually this cheese I made of cow milk and can be sweet or salty; however, when the product is sweet it is generally blended with fruits. ${ }^{1}$

In Brazil, the product is consumed as a dessert primarily by children. ${ }^{2}$ It is well accepted by a growing number of consumers, particularly adults; however, its consumption is low compared to levels in other countries. ${ }^{3}$ Thus, it would be important to obtain information on the consumer acceptability of this product to make inferences about consumer purchase decision-making. ${ }^{4}$

According to Delahunty and Drake, ${ }^{5}$ food acceptance analysis is of extreme importance to understand the degree to which consumers either like or dislike a product. Among the sensory methods available to measure consumer acceptance and preference, the structured ninepoint hedonic scale is the most used and effective method due to the reliability and validity of its results as well as its simplicity of use by consumers. ${ }^{6}$ Currently, data analysis from consumer acceptance test are performed using multivariate methods that take into account individual preferences and not just those of the group average as when using univariate tests (e.g. averages test). ${ }^{7}$

Preference maps are used as multivariate tools in sensory analysis. ${ }^{8}$ Essentially these maps are graphical representations of hedonic scores that allow the identification of each individual along with their preferences in relation to the samples being evaluated. Preference maps may be divided into two categories: internal preference mapping, where analysis is performed only on the set of acceptance/ preference data generated from affective tests, and external preference mapping, where the analysis of some descriptive measurements (such as physicochemical measurements) is included and related to the acceptance/preference data of the products being evaluated. ${ }^{9}$

The classic internal preference map is obtained using Principal Component Analysis (PCA) and allows graphical visualization of the samples that were given the highest hedonic scores in the consumer acceptance analysis and allows the determination of similarities or differences among the samples as a function of the hedonic scores obtained. ${ }^{10,11}$. However, this analysis allows for the evaluation of only one attribute (e.g., appearance, taste or overall appearance) at a time. Taking into consideration that the overall acceptance of the products evaluated by consumers is dependent on several variables, it would be desirable to simultaneously consider all attributes in internal preference maps. However, this is not possible using PCA due to the nature of the data. ${ }^{12}$

The Parallel Analysis Factor (PARAFAC) is a method for the decomposition of higher order data and can be considered a generalization of PCA for multidimensional data. ${ }^{13,14}$ While PCA provides an exploratory analysis of $\mathrm{i}$ samples as a function of $\mathrm{j}$ variables, PARAFAC is able to provide an exploratory interpretation of those samples and variables but also takes into account the different $\mathrm{K}$ conditions under which those data were generated. PARAFAC is able to decompose a matrix I x J x K, that in the case of the internal preference mapping studies, is a set of products $\mathrm{x}$ consumers $\mathrm{x}$ attributes. This method allows the construction of three-way internal preference maps and the simultaneous evaluation of several sensory attributes. ${ }^{12}$ Three-way internal preference mapping is a useful tool for the analysis of consumer acceptance tests, making it possible to simultaneously analyze the interactions among consumer preferences, products and the different attributes evaluated. Furthermore, it enables a comparison of the overall perception of the samples in consumer 
acceptance tests-simultaneously taking into account the influence of all analyzed attributes. ${ }^{15}$ Three-way external preference mapping, on the other hand, uses external data to correlate the acceptability of products and, thus, know the reasons for preferences for such products. ${ }^{16}$

Therefore, this study aimed to evaluate the sensory profile of five brands of strawberry flavor petit suisse cheese, while considering the attributes of color, appearance, taste, texture and overall liking, using three-way internal preference mapping and to correlate the physical and physicochemical analyses with the acceptance data through the three-way external preference mapping.

\section{Material and methods}

\section{Materials}

Investigated were five brands of strawberry flavor petit suisse cheese purchased at the local market in the city of Lavras - MG. Samples with the same manufacturing date were selected. The brands studied were designated $\mathrm{B} 1, \mathrm{~B} 2, \mathrm{~B} 3, \mathrm{~B} 4$, and $\mathrm{B} 5$ to protect the manufacturer identity. While it was recognized that there would have been variations in the manufacturing process and the nature/ proportion of ingredients used in the various brands, the only identifiable variation based on label declarations was with respect to the hydrocolloid bulking agents added. Table 1 shows the bulking agents specified on the product labels.

Table I Bulking agents specified on the label of each brand

\begin{tabular}{ll} 
Brands & Bulking Agents \\
\hline BI & Guar and carrageenan gums \\
B2 & Gelatin and guar gum \\
B3 & Locust bean gum, pectin and gelatin \\
B4 & Modified starch, jatai gum, carrageenan and xanthan gums \\
B5 & $\begin{array}{l}\text { Guar gum, carboxy methyl cellulose, carrageenan and xanthan } \\
\text { gums }\end{array}$ \\
\hline
\end{tabular}

\section{Sensory evaluation}

Sensory analysis was performed in the laboratory of Sensory Analysis, Food Science Department, Federal University of Lavras (UFLA). An acceptance test was conducted on the attributes of color, appearance, taste, texture and the overall liking using a hedonic scale of 9 points $(1=$ dislike extremely $9=$ like extremely $) .{ }^{17}$

The test was conducted on 80 participants ( 45 women and 35 men), among them students and office staff aged between 18 and 40 years. Consumers are randomly recruited from a recruitment survey, the selection was made based on their regular consumption of petit suisse cheese (once or more per week), availability and interest to participate and absence of any kind of allergy to the ingredients listed on the petit suisse label.

Samples of approximately $10 \mathrm{~g}$ of samples ${ }^{18}$ were served in $50 \mathrm{~mL}$ cups refrigeration temperature $\left(7^{\circ} \mathrm{C}\right)$ in a balanced manner. The cups were coded with three-digit numbers drawn from a table of random numbers. The test was conducted in individual booths under white light, with adequate ventilation. Tasters were offered enough water for the analysis. The laboratory temperature was set at $23^{\circ} \mathrm{C}$.

\section{Physicochemical and physical analysis}

The concentration of soluble solids was determined by refractometer reading at $20.0^{\circ} \mathrm{C} .{ }^{19}$ Total acidity was determined by titration with $0.1 \mathrm{~mol} \mathrm{~L}^{-1} \mathrm{NaOH}$, and the results were expressed as a percentage of lactic acid. ${ }^{19}$ Sugars were determined by the method of Antrona according to Dische. ${ }^{20}$ In this study, the gravimetric method, which is based on the loss of weight of a sample dried to constant weight at $105.0^{\circ} \mathrm{C}$, was used for determining moisture content. ${ }^{19}$ All analyses were performed in triplicate.

The colour of the petit suisse cheeses was determined according to the method described by Lau et al. ${ }^{21}$ The values of $L^{*}, a^{*}$ and $b^{*}$ were determined by the Minolta CR 400 colorimeter with D65 (daylight) and CIELab patterns, where $\mathrm{L}^{*}$ ranges from 0 (black) to 100 (white), $\mathrm{a}^{*}$ varies from green $(-)$ to red $(+)$, and $\mathrm{b}^{*}$ ranges from blue (-) to yellow $(+)$.

The texture profile of different brands of Petit-suisse cheese was determined in a Stable Micro Systems TA-XT2i Model (Goldaming, England) texturometer. Analyses were performed at a pre-test speed of $1.0 \mathrm{~mm} \mathrm{~s}^{-1}$, test speed of $1.0 \mathrm{~mm} \mathrm{~s}^{-1}$ and post-test speed of $2.0 \mathrm{~mm}$ $\mathrm{s}^{-1}$ with a compression distance of $10.0 \mathrm{~mm}$ using a $6.0 \mathrm{~mm}$ diameter stainless steel cylindrical probe. The physical parameters analyzed correspond to hardness, cohesiveness and gumminess descriptors. ${ }^{22}$

\section{Experimental design and data analysis}

A completely randomized design was utilized in this study. The results obtained from the physical, physicochemical and sensory analysis were analyzed by means of a univariate statistical analysis (ANOVA) and Tukey averages test to verify the difference between petit Suisse cheese $(\mathrm{p} \leq 0.05)$ using the Sisvar software. ${ }^{23}$

The consumer acceptance data for the different brands of Petitsuisse cheese were analyzed by the three-way internal preference map obtained by PARAFAC. According to the procedure described by Nunes et al, ${ }^{12}$ the data were organized into a three-way matrix from stacked matrices (consumer x samples) of the acceptance attributes.

The physical and physicochemical data $\left(\mathrm{L}^{*}, \mathrm{a}^{*}, \mathrm{~b}^{*}\right.$, moisture, total sugars, soluble solids, total acidity, hardness, cohesiveness and gumminess) were analyzed by three-way external preference map obtained by PARAFAC. ${ }^{12}$ A three-way was arranged from matrices of $i$ rows ( 5 samples $)$ and $j+m$ columns $(80$ consumers +10 physical and physicochemical measurements). ${ }^{24}$

The PARAFAC models were optimized using the value of Core Consistency Diagnostics (CORCONDIA) to choose the number of factors. ${ }^{12,13,24}$ Maps were obtained with the SensoMaker program version $1.0 .{ }^{25}$

\section{Results and discussion}

Table 2 presents the means of the physicochemical, physical and sensory analyses for different brands of strawberry flavor petit suisse. In general, there was variation in the results obtained for all analyzes of the petit suisse.

Mean values with common letters in the same line indicate that there is no significant difference among samples $(\mathrm{p} \leq 0.05)$ from Tukey's mean test. 
Table 2 Means values of the physicochemical, physical and sensory analyses for different brands of strawberry flavor petit suisse

\begin{tabular}{llllll}
\hline Analysis & B I & B2 & B3 & B4 & B5 \\
\hline Total sugar (g100-1) & $39.68 \mathrm{a}$ & $21.44 \mathrm{~b}$ & $34.61 \mathrm{a}$ & $28.68 \mathrm{~b}$ & $26.12 \mathrm{~b}$ \\
Total acidity (\%) & $0.52 \mathrm{a}$ & $0.44 \mathrm{a}$ & $0.44 \mathrm{a}$ & $0.32 \mathrm{a}$ & $0.32 \mathrm{a}$ \\
Moisture (\%) & $70.08 \mathrm{a}$ & $77.77 \mathrm{a}$ & $81.78 \mathrm{a}$ & $75.43 \mathrm{a}$ & $75.75 \mathrm{a}$ \\
L* & $78.00 \mathrm{a}$ & $76.33 \mathrm{a}$ & $79.08 \mathrm{a}$ & $78.31 \mathrm{a}$ & $77.62 \mathrm{a}$ \\
a* & $9.47 \mathrm{~b}$ & $13.84 \mathrm{a}$ & $9.25 \mathrm{~b}$ & $12.2 \mathrm{a}$ & $8.16 \mathrm{~b}$ \\
b* & $7.92 \mathrm{a}$ & $6.67 \mathrm{~b}$ & $6.58 \mathrm{~b}$ & $9.01 \mathrm{a}$ & $5.78 \mathrm{~b}$ \\
Soluble Solids ( $\left.{ }^{\circ} \mathrm{Bx}\right)$ & $17.5 \mathrm{a}$ & $7.67 \mathrm{c}$ & $11.67 \mathrm{~b}$ & $9.17 \mathrm{c}$ & $8.67 \mathrm{c}$ \\
Hardness (N) & $5.85 \mathrm{ab}$ & $5.42 \mathrm{~b}$ & $6.40 \mathrm{a}$ & $6.65 \mathrm{a}$ & $5.44 \mathrm{~b}$ \\
Cohesiveness & $0.65 \mathrm{c}$ & $0.59 \mathrm{~d}$ & $0.77 \mathrm{a}$ & $0.71 \mathrm{~b}$ & $0.59 \mathrm{~d}$ \\
Gumminess (N) & $3.79 \mathrm{~b}$ & $3.19 \mathrm{~b}$ & $4.97 \mathrm{a}$ & $4.76 \mathrm{a}$ & $3.20 \mathrm{~b}$ \\
Color & $6.80 \mathrm{~b}$ & $7.80 \mathrm{a}$ & $7.30 \mathrm{ab}$ & $7.80 \mathrm{a}$ & $4.90 \mathrm{c}$ \\
Appearance & $6.50 \mathrm{~b}$ & $7.30 \mathrm{a}$ & $7.60 \mathrm{a}$ & $7.70 \mathrm{a}$ & $5.30 \mathrm{c}$ \\
Taste & $6.80 \mathrm{a}$ & $5.70 \mathrm{~b}$ & $6.90 \mathrm{a}$ & $5.70 \mathrm{~b}$ & $6.80 \mathrm{a}$ \\
Consistency & $6.90 \mathrm{ab}$ & $6.70 \mathrm{~b}$ & $7.50 \mathrm{a}$ & $7.30 \mathrm{ab}$ & $6.60 \mathrm{~b}$ \\
Overall liking & $6.70 \mathrm{a}$ & $6.20 \mathrm{a}$ & $7.10 \mathrm{a}$ & $6.60 \mathrm{a}$ & $6.30 \mathrm{~b}$ \\
\hline & & & & & \\
\hline
\end{tabular}

It can be seen that samples B1 and B5 were the least preferred. Samples B2 and B3 stood out from the other samples due to the high number of consumers around them. Therefore, these samples were preferred by consumers, this preference is justified by the good performance in all attributes evaluated, i.e., high average hedonic scores for the attributes color, appearance, taste, texture and overall impression (Table 2). Sample B4 had intermediate acceptance between samples B2 and B3 and samples B1 and B5.

Veiga et al, ${ }^{26}$ in studies with different Brazilian petit suisse cheeses, found that out of the six of the studied trademarks, two have gained more acceptance and another two obtained low sensory acceptance in relation to the attributes taste and overall impression.

In the present study it was observed that the most accepted samples were those made with gelatin, pectin and locust bean and guar gums (Figure 1). According Karim and Bhat, ${ }^{27}$ Pereira et al. ${ }^{28}$ and Lima et al. ${ }^{29}$ among commercial hydrocolloids used in the food industry, gelatin, pectin and locust bean and guar gums have been regarded as special and unique, serving multiple functions with a wide range of applications in various industries promoting good acceptability in the elaborated products.

With the purpose of correlating the physical and physicochemical analysis with the acceptance data for the different petit suisse cheese samples, the three-way external preference map was generated (Figure 2).

The external preference mapping indicates that samples B2 and B3 were the best accepted (Figure 2). The map suggests a high correlation of that increased acceptance with higher values of the parameters associated with texture (cohesiveness, gumminess and hardness), color ( $\mathrm{L}^{*}, \mathrm{a}^{*}$ and $\left.\mathrm{b}^{*}\right)$ and moisture, as shown in Table 2, indicating that consumers prefer a more bluish product (lowest value of $b^{*}$ ). Veiga et $\mathrm{al},{ }^{26}$ in his work with different brands of Brazilian petit suisse, states that the terms cited by the team of consumers suggest that the highest consistency brings about a greater acceptance.

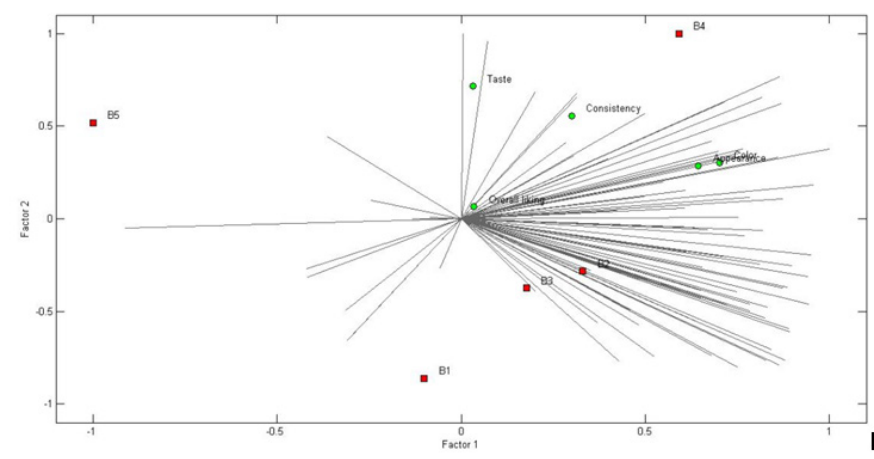

Figure I Three-way internal preference map for color, appearance, taste, consistency and overall liking obtained for the different brands of strawberry flavor petit suisse. Consumers are represented by vectors, samples by squares and acceptance attributes by circles.

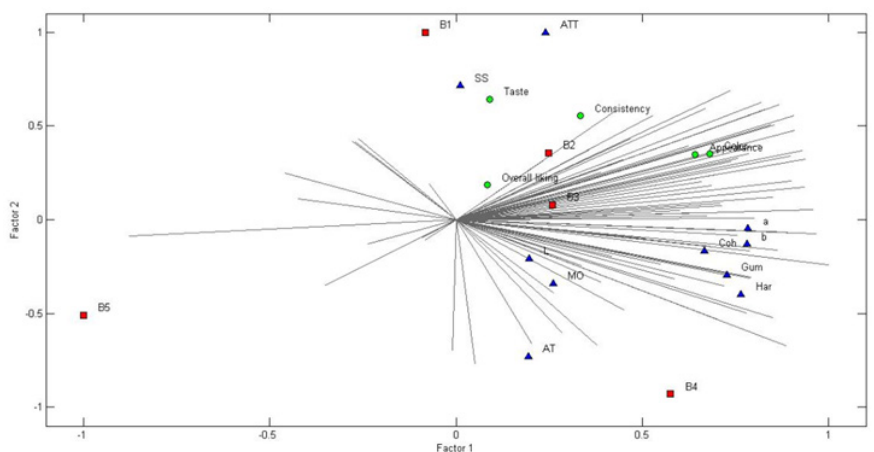

Figure 2 Three-way external preference map for color, appearance, taste, consistency, overall liking, MO (moisture), color parameters ( $\left.\mathrm{L}^{*}, \mathrm{a}^{*} \mathrm{e} \mathrm{b}^{*}\right)$, total acidity (ATT), soluble solids (SS), total sugar (AT), Coh (cohesiveness), Gum (gumminess) and Har (hardness) for the different brands of strawberry flavor petit suisse cheese.

Samples B2 and B3 showed intermediate total soluble solids levels $\left(7.67{ }^{\circ} \mathrm{Bx}\right.$ and $11.67^{\circ} \mathrm{Bx}$, respectively). Thus, one can see that consumers prefer samples with intermediate sweetness.

The preference map indicates that sample B1 and B5 were the least accepted. In relation to sample B1 the external preference map indicates that this sample was influenced by the values of acidity, soluble solids and taste. Table 2 indicates that sample B1 has a higher average soluble solids value $(\mathrm{p} \leq 0.05)$. Thus, it can be inferred that consumers do not like petit suisse cheese with high sweetness. Figure 2 suggests that sample B5 does not indicate a relationship between preference/acceptance of this sample with the analyses performed, suggesting that this decreased acceptance may have been in relation to other features.

\section{Conclusion}

One can conclude from this study that Brazilian consumers prefer petit suisse cheese that has intermediate sweetness and reject those that are very sweet. 
The study also demonstrated that there is some variation in the formulations of the petit suisse cheeses that are currently marketed in Brazil. However, products made with gelatin, pectin and locust bean and guar gums are more accepted.

\section{Funding}

None.

\section{Acknowledgments}

None.

\section{Conflicts of interest}

The authors declare that there was no conflict of interest.

\section{References}

1. Bermudez Beltrán KA, Marzal Bolaño JK, Olivera Martínez AB, et al. Cape gooseberry Petit Suisse Cheese incorporated with moringa leaf powder and gelatin. LWT-Food Sci Technol. 2020;123.

2. Cardarelli HR, Saad SMI, Gibson GR, et al. Functional petit-suisse cheese: Measure of the prebiotic effect. Anaerobe. 2007;13(5-6):200207.

3. Esmerino EA, Paixão JA, Cruz AG, et al. Survival analysis: A consumerfriendly method to estimate the optimum sucrose level in probiotic petit suisse. J Dairy Sci. 2015;98(11):7544-7551.

4. Villegas B, Carbonell I, Costell E. Acceptability of milk and soymilk vanilla beverages: Demographics consumption frequency and sensory aspects. Food Sci Technol Int. 2009;15(2):203-210.

5. Delahunty CM, Drake MA. Sensory characteristics of cheese and its evaluation. In: editors, PF Fox, PLH McSweeney, TM Cogan, et al, Cheese, Chemistry, Physics and Microbiology. Elsevier: UK. 2004.

6. Xia Y, Song J, Zhong F, et al. The 9-point hedonic scale: using R index preference measurement to compute effect size and eliminate artifactual ties. Food Res Int. 2020;133:109140.

7. Zhang $\mathrm{H}$, Huang $\mathrm{D}, \mathrm{Pu} \mathrm{D}$, et al. Multivariate relationships among sensory attributes and volatile components in commercial dry porcini mushrooms (Boletus edulis). Food Res Int. 2020;133:109112.

8. Mukhopadhyay SP, Saliba AJ, Carr BT, et al. Sensory profiling and preference mapping of Australian puffed desi chickpeas. LWT-Food Sci Technol. 2018;89:229-236.

9. MacFie HJH, Thomson DMH. Preference Mapping and Multidimensional Scaling. In: editors, JR Piggot. Sensory Analysis of Foods. 2nd ed., Elsevier: UK;1988.

10. Lawlor JB, Delahunty CM, Wilkinson M, et al. Swiss-type and swisscheddar hybrid-type cheeses: effects of manufacture on sensory character and relationships between the sensory attibutes and volatile compounds and gross compositional constituents. Int J Dairy Technol. 2003;56(1):39-51.

11. Moreno-Rojas R, Cámara-Martos F, Sánchez-Segarra PJ, et al Influence of manufacturing conditions and discrimination of Northern Spanish cheeses using multi-element analysis. Int J Dairy Technol. 2012;65(4):1-9.
12. Nunes CA, Pinheiro ACM, Bastos SC. Evaluating consumer acceptance tests by three-way internal preference mapping obtained by parallel factor analysis (Parafac). J Sens Stud. 2011; 26(2):167-174.

13. Bro R. PARAFAC. Tutorial and applications. Chemometr Intell Lab Syst. 1997;38(2):149-171.

14. Dufour É. Recent advances in the analysis of dairy product quality using methods based on the interactions of light with matter. Int J Dairy Technol. 2011;64(2):153-165.

15. Cariou V, Verdun S, Qannari EM. Quadratic PLS regression applied to external preference mapping. Food Qual Prefer. 2014;32:28-34.

16. Worch T. PrefMFA, a solution taking the best of both internal and external preference mapping techniques. Food Qual Prefer. 2013;30(2):180-191.

17. Stone H, Bleibaum R, Thomas HA. Sensory Evaluation Practices, $4^{\text {th }}$ ed Science Direct: USA; 2012.

18. Acosta O, Víquez F, Cubero E. Optimization of low calorie mixed fruit jelly by response surface methodology. Food Qual Prefer. 2008;19(1):79-85.

19. AOAC. Official Methods of Analysis, 19th edition. AOAC International: USA; 2012.

20. Dische Z. General color reactions. In: editors, RL Whistler, ML Wolfram. Carbohydrate chemistry. New York: Academic; 1962; 477-512.

21. Lau MH, Tang J, Swanson BG. Kinetics of textural and colour changes in green asparagus during thermal treatments. J Food Eng. 2000;45(4):231-236.

22. Herrero AM, Ordónez JA, Avila R, et al. Breaking strength of dry fermented sausages and their correlation with texture profile analysis (TPA) and physico-chemical characteristics. Meat Sci. 2007;77(3):331338

23. Ferreira DF. Sisvar: a Guide for its Bootstrap procedures in multiple comparisons. Ciênc Agrotec. 2014;38(2):109-112.

24. Souza VR, Pereira PAP, Pinheiro ACM, et al. Evaluation of the jelly processing potential of raspberries adapted in Brazil. J Food Sci. 2014;79(3):S407-S412.

25. Nunes CA, Pinheiro ACM. SensoMaker: User guide. Universidade Federal de Lavras. 2012.

26. Veiga PG, Cunha RL, Viotto WH, et al. Chemical, rheological and sensory acceptance Brazilian petit suisse cheese. Ciênc Tecnol Aliment. 2000;20(3):349-357.

27. Karim AA, Bhat R. Gelatin alternatives for the food industry: recent developments, challenges and prospects. Trends Food Sci Technol. 2008;19(12):644-656.

28. Pereira PAP, Souza VR, Vieira MA, et al. Sugar-free guava preserve: influence of additives on textural properties. Int Food Res J. 2017;24(6):2377-2386.

29. Lima MB, Domingos FM, Lima JJFJ, et al. Characterization and influence of hydrocolloids on low caloric orange jellies. Emir J Food Agric. 2019;31(1):7-15. 